\title{
Plasticity of gene expression according to salinity in the testis of broodstock and F1 black-chinned tilapia, Sarotherodon melanotheron heudelotii
}

Jean-Christophe Avarre, Bruno Guinand, Rémi Dugué, Jacky Cosson, Marc Legendre, Jacques Panfili, Jean-Dominique Durand

The black-chinned tilapia Sarotherodon melanotheron heudelotii Rüppell 1852 (Teleostei, Cichlidae) displays remarkable acclimation capacities. When exposed to drastic changes of salinity, which can be the case in its natural habitat, it develops quick physiological responses and keeps reproducing. The present study focused on the physiological impact of salinity on male reproductive capacities, using gene expression as a proxy of acclimation process. Two series of experimental fish were investigated: the first one was composed of fish maintained in freshwater for several generations and newly acclimated to salinities of 35 and 70, whereas the second one consisted of the descendants of the latter born and raised under their native salinity. Expression patterns of 43 candidate genes previously identified from the testes of wild males was investigated in the three salinities and two generations. Twenty of them showed significant expression differences between salinities, and their predicted function revealed that most of them are involved in the osmotic tolerance of sperm cells and/or in the maintenance of sperm motility. A high level of expression variation was evidenced, especially for fish maintained in freshwater. In spite of this, gene expression patterns allowed the differentiation between fish raised in freshwater and those maintained in hypersaline water, in both generations. Altogether, the results presented here suggest that this high variability of expression is likely to ensure the reproductive success of this species under varying salinities. 
1 Plasticity of gene expression according to salinity in the testis of broodstock and F1 black-

2 chinned tilapia, Sarotherodon melanotheron heudelotii

3 Jean-Christophe Avarre ${ }^{1 *}$, Bruno Guinand ${ }^{1}$, Rémi Dugué ${ }^{1}$, Jacky Cosson ${ }^{2}$, Marc Legendre ${ }^{1}$, 4 Jacques Panfili ${ }^{3}$, Jean-Dominique Durand ${ }^{3}$

$5{ }^{1}$ Institut des Sciences de l'Evolution de Montpellier, UMR 226 IRD-CNRS-UM2, Montpellier,

6 France

$7{ }^{2}$ University of South Bohemia in Ceske Budejovice, Faculty of Fisheries and Protection of

8 Waters, South Bohemian Research Center of Aquaculture and Biodiversity of Hydrocenoses,

9 Research Institute of Fish Culture and Hydrobiology, Vodňany, Czech Republic

$10{ }^{3}$ Ecologie des Systèmes Marins Côtiers, UMR 5119 IRD-UM2-CNRS-IFREMER, Montpellier,

11 France

12 *Corresponding author:

13 Jean-Christophe Avarre

14 Institut des Sciences de l'Evolution de Montpellier, IRD, UMR 226

15 Université Montpellier II, Bat 22, CC 065

16 Place Eugène Bataillon

1734095 Montpellier cedex 05, France

18 Tel: +33467143480 , fax: +33467143622

19 jean-christophe.avarre@ird.fr

20 Short title: salinity and gene expression in tilapia testis 


\section{PeerJ Reviewing Manuscript}

\section{Introduction}

22 The black-chinned tilapia, Sarotherodon melanotheron heudelotii Rüppell 1852 (Teleostei,

23 Cichlidae), is a mouth-brooding fish that mainly occurs in estuarine and lagoon ecosystems of

24 West Africa, but also sometimes in isolated, natural or artificial ponds. This species is an

25 important local fish resource, accounting for a large part of catches in this area. Because of

26 reduced freshwater input and intense evaporation that has occurred over the last years (Pagès \&

27 Citeau 1990; Savenije \& Pages 1992), it is regularly exposed to changes of salinity in its natural

28 habitats. This led to physiological modifications of osmoregulation (Lorin-Nebel et al. 2012; Tine

29 et al. 2011) and reproductive strategies (Gueye et al. 2012; Legendre et al. 2008; Panfili et al.

30 2004; Panfili et al. 2006).

31 Analysis of the gene expression patterns in the gills of this species evidenced a clear

32 differentiation of sub-populations along the Sine Saloum estuary (Senegal) linked to the ambient

33 salinity (Tine et al. 2012). It was also demonstrated that salinity induced phenotypic

34 modifications of the mechanisms involved in the activation of sperm cell motility, one of the

35 major indicators of male fitness (Fauvel et al. 2010; Lahnsteiner et al. 1998). Indeed, the

36 osmolality that enabled sperm activation in the black-chinned tilapia increased significantly with

37 the salinity at which broodfish were maintained (Legendre et al. 2008). This finding was also

38 recently reported for another estuarine species, Fundulus grandis (Tiersch \& Yang 2012),

39 indicating that increased knowledge in $S . m$. heudelotii could also benefit other euryhaline 40 species.

41 Most of the studies focusing on the response of aquatic animals to alternative osmotic (Evans

42 \& Somero 2008; Larsen et al. 2007; Whitehead \& Crawford 2006; Whitehead et al. 2011) or

43 hypoxic (Gracey 2007; Rathburn et al. 2013; Tiedke et al. 2014) environments addressed this

44 question through functional genomics of the gills and/or liver. Nevertheless, the fitness of

45 individuals does not only rely on short-term, direct physiological responses to environmental 
46 challenges, but also on their capacity to produce viable gametes and offspring under a wide range

47 of environmental conditions (Breckels \& Neff 2013; Dorts et al. 2012). Salinity has been shown

48 to significantly modify some reproductive traits such as length at first sexual maturity, fecundity

49 and oocyte size in the wild (Diouf et al. 2009; Panfili et al. 2004; Panfili et al. 2006; Whiterod \&

50 Walker 2006). However, very few studies attempted to investigate how gene expression in gonads

51 responded to salinity challenges, even though gametogenesis and gamete quality may be highly

52 influenced by salinity (Alavi \& Cosson 2006; Bobe \& Labbé 2010; Cosson 2004).

53 Using a high-throughput transcriptomic approach, Avarre et al. (Avarre et al. 2014) validated a

54 de novo qPCR assay complying with the MIQE (Minimum Information for publication of 55 Quantitative real-time PCR Experiments) guidelines (Bustin et al. 2009) for 43 candidate and 11 56 reference gene transcripts in the testes of mature males sampled in Senegal at locations 57 displaying salinities of 40 and 95 . The aim of the present study was to examine the putative 58 involvement of the expression pattern of these 43 candidate genes in the acclimation of male 59 reproductive capacities to salinity changes, over two generations. More specifically, it 60 investigated (i) how transfer from low (0) to high salinities (35 and 70) induced specific changes 61 of gene expression in testes within a single parental generation, and (ii) if these variations 62 persisted in the next generation $\left(\mathrm{F}_{1}\right)$. Two series of experimental fish were analyzed: the first one 63 was composed of fish maintained in freshwater and newly acclimated to salinities of 35 and 70 64 ("transferred fish", $T$ ), whereas the second one consisted of the $\mathrm{F}_{1}$ descendants of $\mathrm{T}$ fish. These $\mathrm{F}_{1}$ 65 individuals were born and raised in each salinity condition ("born fish", B). Levels of gene 66 expression were compared between the two generations in order to bring insights into the 67 mechanisms that allow $S$. melanotheron males to respond to salinity changes without 68 compromising the success of reproduction.

\section{Material and methods}


71 The fish used in this study came from a single freshwater strain of Sarotherodon melanotheron

72 heudelotii. They originated from a population of $\sim 50$ juveniles sampled in the Niayes (natural 73 freshwater ponds) of Dakar (Senegal) and transferred to our facilities (Montpellier) nearly 15

74 years ago. Since then, fish have been reared in freshwater recirculation systems (i.e. in the same

75 salinity as that of their natural environment). In order to minimize the loss of genetic diversity, 3-

7610 mate pairs were used to obtain a new generation, and one generation corresponded to

77 approximately 18 months. Twelve mature males and twelve mature females (approximately 18

78 month old) from this pool (hereafter referred to as T) were transferred to 3 independent water

79 recirculation systems dedicated to a specific salinity (i.e. 0,35 and 70 ). These salinities mimic

80 fresh, saline and hypersaline waters in which $S$. melanotheron heudelotii may be frequently

81 encountered in the wild. Yet, because of technical limitations, experiments with higher water

82 salinities were not implemented here. Each system comprised two breeding tanks (polyester tanks

83 of $2.5 \mathrm{~m}$ length $\times 0.53 \mathrm{~m}$ width $\times 0.30 \mathrm{~m}$ depth). Water salinity was gradually increased at a rate

84 of about 1 day $^{-1}$ by the addition of synthetic sea salt ("Instant Ocean", Aquarium system,

85 Sarrebourg, France) until the target salinities of 35 and 70 were reached. Following a 5-week

86 period of acclimation at the final salinities, fish were monitored for their reproductive behaviour

87 over 18 weeks. Specifically, male reproductive success was assessed through the number of

88 incubating males per tank (related to the number of available couples), the effective fertilization

89 of incubated eggs and the viability of progenies. Finally, they were anaesthetized (Eugenol, 0,1

$90 \mathrm{~mL} / \mathrm{L}$ ) and then killed by an overdose of anaesthetic (Eugenol, 0,5 mL/L) in ice (in accordance

91 with the EU Directive 2010/63/EU) for dissection and testis collection. The body weight (Wb),

92 fork length (FL) and gonad weight (Wg) were recorded for each fish, and the gonadosomatic

93 index (GSI) was calculated as follow: Wg / Wb x 100. Condition factor K was also calculated, 
94 according to the standard formula $100 \times \mathrm{Wb} / \mathrm{FL}^{3}$. During this period, about 50 hatchlings from

95 6-8 spawning events per salinity were transferred to another series of tanks. They were grown at

96 salinities of 0,35 and 70 until they were 9-11 months old, i.e. about 3 months after they became

97 sexually mature. From these large pools of animals (referred to as B), 12 males and 12 females

98 per salinity condition were randomly selected and transferred to the same breeding tanks used for

99 T animals. Again, their reproductive activity was monitored for 18 consecutive weeks before they

100 were processed for testis collection as indicated above. Testes were placed in RNA later

101 (Ambion) overnight at $4^{\circ} \mathrm{C}$ and then stored at $-20^{\circ} \mathrm{C}$ until use. In total, testes from $33 \mathrm{~T}$ and $35 \mathrm{~B}$

102 fish were collected (Figure 1). All the experimental procedures took place in our facilities in

103 Montpellier, under the laboratory agreement for animal experimentation number A-34-172-24

104 and the author's personal authorization for animal experimentation number 34-188, both 105 delivered by the French government.

\section{RNA extraction and cDNA synthesis}

107 RNA was extracted with the Nucleospin-8 total RNA isolation kit (Macherey-Nagel). Fifteen to 108 twenty $\mathrm{mg}$ of testis preserved in RNA later were weighed and transferred into $2 \mathrm{ml}$ tubes 109 containing a $5 \mathrm{~mm}$ steel bead (Qiagen) as well as $360 \mu 1$ lysis buffer supplemented with $1 \% \beta$ -

110 mercaptoethanol (Sigma-Aldrich). Tissues were homogenized with a tissue lyzer (Qiagen) for 2

$111 \mathrm{~min}$ at $50 \mathrm{~Hz}$. Tubes were then centrifuged for $5 \mathrm{~min}$ at full speed and the supernatants were

112 transferred to new tubes and kept at $-20^{\circ} \mathrm{C}$ overnight. RNA was extracted the following day

113 according to the manufacturer's instructions, using a Janus automated workstation (Perkin

114 Elmer), and eluted in $70 \mu \mathrm{l}$ RNase-free $\mathrm{H}_{2} \mathrm{O}$. In order to remove any trace of contaminating 115 genomic DNA, RNA eluates were subjected to a second DNase treatment: a mix of $0.2 \mu 1$ of 116 RNase-free DNase and $2 \mu 1$ of reaction buffer (Macherey-Nagel) was added to $20 \mu 1$ of each 
117 RNA eluate, and digestion was carried out for $15 \mathrm{~min}$ at $37^{\circ} \mathrm{C}$. RNA quantity was measured by

118 UV spectrophotometry (Nanodrop 1000, Thermoscientific), and its integrity was verified by

119 capillary electrophoresis (Agilent Bioanalyzer 2100). Each RNA sample was diluted to a 120 concentration of $50 \mathrm{ng} \cdot \mu \mathrm{l}^{-1}$ in $\mathrm{H}_{2} \mathrm{O}$ and stored at $-80^{\circ} \mathrm{C}$.

121 Reverse transcription was performed with oligodT primers on $250 \mu \mathrm{g}$ RNA, using the 122 transcriptor first strand cDNA synthesis kit (Roche). A template-primer mixture consisting of 250 $123 \mu \mathrm{g}$ RNA and $2.5 \mu \mathrm{M}$ oligodT was denatured at $65^{\circ} \mathrm{C}$ for 10 -min and immediately cooled on ice. 124 The reaction (in $20 \mu \mathrm{l}$ final) was supplemented with reaction buffer (1X), dNTPs (1 mM each),

125 RNase inhibitor $(20 \mathrm{U})$ and reverse transcriptase $(10 \mathrm{U})$, incubated for $1 \mathrm{hr}$ at $50^{\circ} \mathrm{C}$, then heated

126 for $5 \mathrm{~min}$ at $85^{\circ} \mathrm{C}$ and immediately cooled on ice. The resulting cDNAs were diluted 10 times 127 with $180 \mu 1 \mathrm{H}_{2} \mathrm{O}$ and stored at $-20^{\circ} \mathrm{C}$ until use.

\section{Gene sequence annotation}

129 The candidate and reference genes investigated here were identified using a high-throughput 130 digital gene expression approach (Avarre et al. 2014). Their raw sequences can be found under

131 the SRA study accession number SRP022935, whereas the assembled sequences can be accessed 132 through a freely accessible interactive database

133 (http://asahttp.drim.com/tilapia/tilapia_menu.php). Annotation of the corresponding sequences

134 was therefore needed to infer their putative functions. This was realized with Blast2GO v2.6.6

135 (Conesa et al. 2005). Sequences were used as a query to search the non-redundant protein 136 database available at the National Center for Biotechnology Information (www.ncbi.nlm.nih.gov)

137 using the BlastX algorithm with an E-value cutoff set at $10^{-6}$. Sequences were then functionally

138 annotated by mapping against gene ontology (GO) resources. Sequences that were not assigned 139 any GO term were checked for conserved domains using the CD-search tool (Marchler-Bauer \& 
140 Bryant 2004). Likewise, sequences for which the number of BlastX hits was $<5$ were re-aligned

141 using the BlastN algorithm, and their description was corrected when necessary.

\section{Gene expression analysis}

143 The expression of 43 candidate genes previously validated for their potential as being involved in

144 testis response to salinity was analyzed by qPCR at the 3 salinities and for the 2 fish generations.

145 PCR amplifications were carried out in 384-well plates with a LightCycler 480 (Roche) in a final

146 volume of $6 \mu 1$ containing $3 \mu 1$ of SYBR Green I Master mix (Roche), $2 \mu 1$ of cDNA and $0.5 \mu \mathrm{M}$

147 of each primer (Avarre et al. 2014). Amplifications were performed in duplicate with an initial

148 denaturation step of $10 \mathrm{~min}$ at $95{ }^{\circ} \mathrm{C}$ followed by 40 cycles of denaturation at $95^{\circ} \mathrm{C}$ for $10 \mathrm{~s}$,

149 annealing at $60^{\circ} \mathrm{C}$ for $10 \mathrm{~s}$ and elongation at $72^{\circ} \mathrm{C}$ for $10 \mathrm{~s}$. Amplifications were followed by a

150 melting procedure, consisting of a brief denaturation at $95^{\circ} \mathrm{C}$ for $5 \mathrm{sec}$, a cooling step at $65^{\circ} \mathrm{C}$ for

$1511 \mathrm{~min}$ and a slow denaturation to $97^{\circ} \mathrm{C}$. Amplification products were validated by analyzing the

152 shape of their corresponding melting curve and by measuring their size on agarose gel

153 electrophoresis. For each given sample, all the genes were amplified simultaneously in the same

154 384-well plate, and each plate contained a no-template control for every primer pair. Cycle of

155 quantification $(\mathrm{Cq})$ values were calculated with the LightCycler software, using the second

156 derivative method. Results were expressed as changes in relative expression according to the 2

$157 \Delta \Delta C q$ method (Pfaffl 2001). Cq values were first corrected with the amplification efficiency of each

158 primer pair according to the following equation: $\mathrm{Cq}_{\mathrm{E}=100 \%}=\mathrm{Cq}_{\mathrm{E}}(\log (1+\mathrm{E}) / \log (2))$, where $\mathrm{E}$ is

159 the efficiency and $\mathrm{Cq}_{\mathrm{E}}$ the uncorrected $\mathrm{Cq}$ values. Then the corrected Cqs of each gene of interest

160 were normalized $(\Delta \mathrm{Cq})$ with the mean $\mathrm{Cq}$ of 4 validated reference genes (

161 and $\Delta \mathrm{Cq}$ values were related to the average $\Delta \mathrm{Cq}$ value of all samples. 
$163 \mathrm{~T}$ and $\mathrm{B}$ animals maintained in freshwater were initially analyzed as 2 different groups; however,

164 because they belonged to the same salinity treatment and were kept in the same conditions, they

165 were also considered as one single group for statistical purposes. Comparison of the two

166 situations showed that variations in gene expression followed the same trend, indicating that

167 pooling did not mislead interpretation (not shown). All statistical analyses were performed with

168 the GenEx Pro package (MultiD analyses, Sweden). The normality of data distribution was first

169 verified for each series of samples using the Kolmogorov-Smirnov test. Since more than $90 \%$ of

170 series turned out to be normally distributed, a one-way ANOVA test with a Tukey-Kramer's post-

171 test was applied to infer significant differences between salinities, using a confidence level of

$1720.95(p<0.05) . P$-values were corrected for multiple testing using the false discovery rate

173 (Benjamini \& Hochberg 1995). Concurrently, expression levels were also compared by salinity

174 pairs with a $t$-test, using the same confidence level. Finally, a principal component analysis

175 (PCA) was also carried out on the two series of fish, according to the expression pattern of the 176 investigated genes.

\section{Results}

178 In spite of their age difference, average GSI for the two series of fish (T and B) were comparable,

179 with mean $( \pm \mathrm{SD})$ values of $0.27 \pm 0.13$ and $0.26 \pm 0.12$ for $\mathrm{T}$ and $\mathrm{B}$ males, respectively.

180 Condition factor calculated for each salinity group showed similar values, ranging between 1.99

$181 \pm 0.11$ and $2.04 \pm 0.14$. Moreover, spermatozoa produced by the fish investigated in this study led

182 to successful fertilization with viable offspring in all experimental conditions, indicating that

183 salinity did not impair the ability of male to successfully reproduce. 
185 A collective analysis of raw $\mathrm{Cq}$ values for the 43 candidate and 4 reference genes in the $33 \mathrm{~T}$ and

18635 B fish with geNorm (Vandesompele et al. 2002) and NormFinder (Andersen et al. 2004)

187 software indicated that Contig_Tilapia_90_13722 (R1), Contig_Tilapia_90_7452 (R2),

188 Contig_Tilapia_90_3058 (R3) and Transcript_AVA3_453 (R4) were the most stably expressed

189 genes. This confirmed that these four genes were appropriate to use as reference in the present 190 conditions, as was already demonstrated on wild fish (Avarre et al. 2014).

191 Among the 43 tested candidate genes, 20 showed significant variations between fish kept at 192 different salinities in at least one of the 2 generations investigated in this study (Table 1). The 193 number of genes that showed significant variations in their expression levels between salinities 194 was higher in $\mathrm{T}(18)$ than in B (10) animals. The relative expression levels of these genes are 195 displayed in Figures 2 and 3. Generally, fold-changes in relative expression between the different 196 salinity conditions were quite low, as the highest ratio was 3.86. Conversely, inter-individual 197 variations among salinity groups were rather high. Interestingly, these variations were uppermost 198 in fish kept in fresh water. Within each generation, the largest differences were observed between 199 the most extreme salinities, i.e. between 0 and 70, and to a lesser extent between 0 and 35 , as 200 indicated by Tukey-Kramer pairwise comparisons. In $\mathrm{T}$ fish, the number of genes showing 201 significant differences was 11 between fresh and seawater, 15 between fresh and hypersaline 202 water and 2 between saline and hypersaline water. In B fish, these numbers amounted 5, 11 and 2, 203 respectively. Likewise, the largest fold-change differences were also observed between salinities 2040 and 70, for the two series of animals. Overall, directions of expression differences between 205 salinities were comparable in both generations.

206 Results of the PCA, based on the expression pattern of the 20 investigated genes, are displayed 207 in figure 4. The two first PC axes accounted for $87.20 \%$ and $5.40 \%$ of variation. Because the 208 variation explained by the second axis accounted for approximately 17 times less than the first 209 one, an ANOVA with a Tukey-Kramer's pairwise comparison was performed on the PC scores of 
210 the first axis only. It revealed that freshwater males could be significantly differentiated from T35

$211(\mathrm{P}=0.024), \mathrm{T} 70(\mathrm{P}=0.0015)$ and $\mathrm{B} 70(\mathrm{P}=0.0004)$ animals, but not from $\mathrm{B} 35$ ones $(\mathrm{P}>0.05)$.

212 Moreover, there were no significant differences between T35 and B35 animals or between T70

213 and B70 animals $(\mathrm{P}>0.05)$.

214 Predicted function of the differentially expressed and reference genes

215 Except for Contig_Tilapia_90_2321 which returned no significant blastX hit and

216 Transcript_AVA3_33497 which matched a hypothetical protein, all 24 genes could be attributed

217 either a known or a predicted function, with rather low E-values. Among these, 21 could be

218 assigned at least one GO description (Table 2). The list contains proteins for which a putative role

219 in spermatogenesis has already been proven in other organisms (MORC family CW-type zinc

220 finger 2 protein, $28 \mathrm{kDa}$ heat- and acid-stable phosphoprotein, seminal plasma glycoprotein), as

221 well as proteins involved in energy metabolism (NADH dehydrogenases, phosphatase), in stress

222 response and osmoregulation (heat shock proteins, sodium potassium ATPase), or in axonemal

223 activity (calcium-binding protein, beta-tubulin). The predicted function of the 23 remaining

224 genes, which did not show any significant variations according to salinity, is displayed in

225 Supplementary Table 1.

\section{Discussion}

227 This study aimed to analyze how mature males originating from a single freshwater population 228 responded to transfer in saline (salinity 35 ) or hypersaline (salinity 70 ) water, and how $F_{1}$

229 individuals born in these new environments expressed the same genes. Salinity changes were 230 shown to noticeably modify the life-histories and reproductive strategies of populations (Gueye et

231 al. 2012; Legendre et al. 2008; Panfili et al. 2004; Panfili et al. 2006), and to impact their 232 osmoregulatory capacities (Lorin-Nebel et al. 2012; Tine et al. 2012) and their stress response 233 (Tine et al. 2010). Nevertheless, gene expression variation in reproductive organs like testes was 
234 never investigated, although they are necessary to the preservation of male fitness and contribute

235 to the demographic features of populations. Previous results have shown that salinity of the water 236 under which fish were raised had a major effect on sperm characteristics and on the conditions

237 for activation of spermatozoa motility. Particularly, higher osmolality and higher concentrations 238 of extracellular calcium were required for activation of spermatozoa in fish maintained in 239 saline/hypersaline water (Legendre et al. 2008 and unpublished results). The precise mechanisms, 240 and especially the molecular basis behind these physiological adaptations, still need further 241 investigations. However, as intra-testicular spermatozoa and other testicular cell types are 242 particularly difficult to separate, and the quantification of gene expression for each single cell 243 type difficult to reach, studying gene expression variation at the testis level is a necessary step for 244 deciphering the genes involved in salinity acclimation. Physiological changes related to 245 environmental salinity were observed not only at the spermatozoa level (motility activation), but 246 also at the gonad level (e.g. ionic content and osmolarity of the seminal fluid involved in the 247 protection of spermatozoa during storage in the reproductive system) (Legendre et al., 248 unpublished results), indicating that a tissue level approach is necessary.

249 Global expression patterns of the 20 genes distinguished fish that only experienced freshwater 250 from their counterparts acclimated to saline and hypersaline conditions (T35 and T70). This 251 reflected a shift - i.e. a plastic response - in mean levels of gene expression from a standard 252 freshwater environment to a new environment, with no significant differences in global gene 253 expression patterns between T35 and T70 males. Among B animals (i.e. born in a specific 254 salinity), gene expression patterns were found significantly different only between freshwater and 255 B70 males. Inter-individual variation in mRNA levels was found highest for $\mathrm{T}$ and $\mathrm{B}$ fish 256 maintained in freshwater, i.e. the only animals that did not undergo any environmental change for 257 many generations. Concurrently, inter-individual variation in gene expression was around twice 258 lower in T35, B35 and T70 males, and 3 times lower in B70 fish. Elevated inter-individual 
259 variations in mRNA levels have been proposed as a possible source of variation to enable future 260 evolution in reaction to rapid environmental changes (Aubin-Horth et al. 2005; Oleksiak et al. 261 2002; Whitehead \& Crawford 2005; Whitehead \& Crawford 2006), since production of better 262 adapted protein orthologs does not fit such short time-scales ( 263 contrast with gene expression levels, no differences in fertilization capabilities were observed 264 between all investigated fish. If salinity increase induced a shift in the osmolarity at which sperm 265 cells were activated (not shown), it yet did not affect sperm motility itself, and spermatozoa 266 produced by all the fish led to successful fertilization with viable offspring in all experimental 267 situations. This indicates that salinity changes and salinity itself did not impair the ability of 268 males to reproduce successfully. Combined together, these findings suggest that the genes 269 investigated here are involved in the mechanisms of acclimation to salinity. They also support the 270 hypothesis that naturally-occurring expression variation contributes to the phenotypic plasticity 271 of male black-chinned tilapia, which ensures its reproductive success under varying salinities. 272 Nevertheless, this plasticity may differ between $\mathrm{T}$ and $\mathrm{B}$ fish. Indeed, $\mathrm{T}$ fish demonstrated an 273 ability to respond to a punctual, context-dependent change in environmental conditions after 274 being raised in a common environment, a process known as phenotypic flexibility (Piersma \& 275 Drent 2003). In contrast, B fish 'accomodated' their respective saline environment since hatching, 276 and differences in gene expression across treatments might partly originate from the 277 developmental component of gene expression plasticity (West-Eberhard 2003). Yet, the present 278 experimental design does not permit to conclude whether the differences found between $\mathrm{T}$ and $\mathrm{B}$ 279 animals (in terms of gene expression) are due to phenotypic flexibility itself or to the co280 occurrence of both types of plasticity. Detailed studies of these two components of plasticity 281 warrant further investigations in the black-chinned tilapia.

282 Among the 20 genes showing differential expression in the testes, many encode proteins that 283 have a link with the general oxidation-reduction level of sperm cells, and/or participate to plasma 
284 membrane channel activity through differential regulation of ion content. Both activities play an

285 important role in the osmotic tolerance of sperm cells (Morita et al. 2011) and in the maintenance 286 of sperm motility in fish (Alavi \& Cosson 2006). The potential involvement of some of these 287 genes is discussed below.

288 Among the largest variations in gene expression that were observed, gene 1 encodes a protein 289 homologous to type-IV ice-structuring protein, also known as antifreeze protein type-IV 290 (AFPIV). The AFPIV has already been reported in many fishes from cold, temperate and warm 291 waters (Lee et al. 2011), and its role is still subject to question. It was indeed shown to have 292 actual antifreeze ability. However, its low plasma level measured in the longhorn sculpin 293 (Myoxocephalus octodecimspinosis) suggests another function for this protein, such as a role in 294 lipid transport due to its close structure relatedness with that of fish apolipoproteins (Gauthier et 295 al. 2008). Recently, AFPIV was shown to be abundantly synthesized in ovaries of the Atlantic cod 296 (Gadus morhua), especially during late stages of vitellogenesis, and was proposed to be involved 297 in lipid transport and/or metabolism (Breton et al. 2012), in spite of a proven low concentration in 298 the blood of adults (Gauthier et al. 2008). Finally, expression of AFPIV was also demonstrated in 299 embryos of the gibel carp (Carassius auratus gibelio), and the authors proposed a potential role 300 in the embryonic patterning (Liu et al. 2009). Beyond fish, it is known that antifreeze proteins 301 participate to the osmotic resistance of spermatozoa by reducing mechanical stress to the cell 302 membrane. They are hence often used in sperm cryopreservation (Prathalingam et al. 2006). 303 Genes or more generally factors regulating osmolality and ion content are central to sperm 304 motility (Cosson et al. 2008). In both T and B fish, expression of gene 1 significantly decreased 305 with the salinity to which tilapia fish specimens were exposed. Experimental evidence is now 306 required to elucidate the potential role of an antifreeze type IV-related protein in the adaptation to 307 salinity, especially with regard to male gonadic activity and fertility. This is the first time that 308 expression of an AFPIV is reported to occur in testes. 
309 If the expression of the $\mathrm{Na}+/ \mathrm{K}+$ ATPase (NKA) gene has been extensively studied in the gills 310 of fish exposed to different salinities (

311 Nebel et al. 2012; Tine et al. 2008; Tine et al. 2012), this is only the first report of its expression

312 in the testes (gene 3). In gills, NKA plays an essential role in osmoregulation through branchial

313 ionocytes to actively uptake/excrete ions from/to environmental water, respectively. Since testes

314 have no ionocytes, it is likely that NKA plays other roles in the male gonads, and this requires

315 further investigations. Sequence 4 matches a portion of the catalytic subunit of a serine-threonine 316 protein phosphatase. A modulatory role of serine-threonine protein phosphatase in

317 osmoregulation has been demonstrated in fish (Marshall et al. 2005), but details are scarce and

318 the mechanisms still poorly explained, probably because of the myriad of reactions controlled by

319 serine-threonine protein phosphatases (Shi 2009). The involvement of several serine-threonine

320 protein phosphatases in the regulation of sperm motility was recently demonstrated in humans

321 (Fardilha et al. 2013); this research has to be extended to fish. Sequence 5 is similar to that of a

322 seminal plasma glycoprotein that contains both a partial von Willebrand factor type D domain

323 and a zona pellucida (ZP) domain. This high molecular weight glyco-protein was shown to have

324 a sperm-binding activity and a sperm-immobilizing activity (Mochida et al. 2002).

325 The predicted function of gene 15 points to a possible calcium-binding activity. A significant

326 raise of its abundance was observed with salinity in $\mathrm{T}$ animals, suggesting an increase of $\mathrm{Ca}^{2+}$

327 metabolism in the testes of fish exposed to higher salinities. Earlier studies on another euryhaline

328 tilapia, Oreochromis mossambicus, suggested that acclimation of sperm motility to salinity was

329 associated with a modulation of the $\mathrm{Ca}^{2+}$ flow in order to increase its intracellular concentration

330 (Morita et al. 2004). More recent studies on the black-chinned tilapia showed that the osmolality

331 that enabled sperm activation increased significantly with the salinity at which broodfish were

332 maintained. It was also found that increasing amounts of calcium in the sperm activation medium

333 were needed to initiate sperm motility as a function of fish rearing salinity (Legendre et al. 2008). 


\section{PeerJ Reviewing Manuscript}

334 Sequence 16 matches a beta-tubulin, which involvement in the flagellar motility, especially

335 through post-translational modifications, has been shown for a wide range of organisms (Huitorel

336 et al. 1999). The description of gene 17 matches a MORC family CW-type zinc ( $\mathrm{Zn}$ ) finger

337 protein, which absence was first shown to trigger the stop of spermatogenesis in mice (Watson et

338 al. 1998). Zinc is a trace element essential to reproduction in both sexes of numerous mammalian

339 species including humans (Bedwal \& Bahuguna 1994). Its involvement in spermatogenesis was

340 recently shown in the Japanese eel (Anguilla japonica), by activating Zn-finger proteins and

341 modulating transcription factor genes containing Zn-finger motifs (Yamaguchi et al. 2009). It

342 allows for the regulation of mitotic cell proliferation and meiosis, the activation/inactivation of

343 sperm motility, and may also affect the regulation of steroid hormone receptors including

344 androgens (Yamaguchi et al. 2009). .

345 Among the 24 (reference and differentially expressed) genes analyzed in this study, four

346 encode predicted NADH dehydrogenase subunits: two of them showed differential expression

347 between salinities (genes 9 and 10), whereas the other two were used as reference (R1 and R2).

348 Expression of NADH dehydrogenase was already demonstrated to significantly vary with salinity

349 in the gills of the black-chinned tilapia (Tine et al. 2010; Tine et al. 2008; Tine et al. 2012)), but

350 transcripts were not annotated precisely at that time. The two differentially regulated transcripts

351 found in this study correspond to subunits ND1 and NDUFB3/B12, whereas the two sequences

352 used as reference correspond to subunits NDUFV1 and NDUFA10. All of these NADH

353 dehydrogenase subunits are part of a complicated multiprotein complex located in the inner

354 mitochondrial membrane, the NADH:ubiquinone oxidoreductase (complex I). It plays a central

355 role in oxidative phosphorylation and its main function is the transport of electrons by oxidation

356 of NADH followed by reduction of ubiquinone, which is accompanied by the translocation of

357 protons from the mitochondrial matrix to the inter-membrane space (Loeffen et al. 1998). In

358 humans, correlations between sperm quality or sperm motility and mitochondrial activities 
359 including oxidative phosphorylation have been known for a while (Piomboni et al. 2012; $\underline{\text { Ruiz- }}$

360 Pesini et al. 1998). Complex I is composed of 45 different subunits, regulated by both nuclear and 361 mitochondrial genomes (Lazarou et al. 2009). It is therefore not surprising that different subunits

362 may be subjected to differing regulation pathways, depending on available substrates and on the

363 physico-chemical conditions in which they operate, as reported in humans (Piomboni et al. 2012).

364 This was recently shown in fish by a study analyzing the transcriptional regulation during the

365 ovarian development of the Senegalese sole (Solea senegalensis) (Tingaud-Sequeira et al. 2009),

366 but data on male-specific tissues such as testes are lacking. Variations in complex I activity have

367 been reported in many species, especially in the case of altered environments, and a reduction of

368 its activity with water temperature was recently shown in Fundulus heteroclitus (Loftus \&

369 Crawford 2013). In the present study, expression of the two above-mentioned subunits

370 significantly decreased with salinity. This differential expression could be related to the link of

371 complex I with reactive oxygen species (ROS) (Maranzana et al. 2013), which are known to be

372 involved in the control of sperm motility, both in mammals (e Lamirande et al. 1997) and fish

373 (Shaliutina et al. 2014). Indeed, a recent study pointed out a relationship between the oxidation-

374 reduction level and the phosphorylation status of an $18-\mathrm{kDa}$ superoxide anion scavenger protein

375 in the sperm cells of Oreochromis mossambicus, and showed that ROS-dependent mechanisms

376 contributed to the osmotic tolerance of this other euryhaline tilapia (Morita et al. 2011).

\section{Conclusion}

378 The present study enabled the identification of 20 candidate genes likely involved in the 379 acclimation to salinity changes of the reproductive physiology of Sarotherodon melanotheron 380 heudelotii. It evidenced the potential role of unexpected transcripts (such as that encoding an

381 antifreeze protein type-IV), and supported the hypothesis that elevated variations in gene 382 expression may contribute to the remarkable plasticity of this species. Now, the relative 
383 contribution of phenotypic flexibility and developmental plasticity has to be investigated in more

384 details, in order to gain further understanding on the fitness consequences of such changes in 385 testis gene expression.

\section{Acknowledgements}

387 We are very grateful to Mr. Christophe Cochet for his strong involvement in the maintenance of 388 fish welfare. This is publication IRD-DIVA-ISEM-2014-190.

\section{References}

390 Alavi SMH, and Cosson J. 2006. Sperm motility in fishes. (II) Effects of ions and osmolality: A 391 review. Cell Biology International 30:1-14.

Andersen CL, Jensen JL, and Ørntoft TF. 2004. Normalization of Real-Time Quantitative Reverse Transcription-PCR Data: A Model-Based Variance Estimation Approach to Identify Genes Suited for Normalization, Applied to Bladder and Colon Cancer Data Sets. Cancer Research 64:5245-5250.

Aubin-Horth N, Landry CR, Letcher BH, and Hofmann HA. 2005. Alternative life histories shape brain gene expression profiles in males of the same population. Proceedings of the Royal Society B: Biological Sciences 272:1655-1662.

Avarre JC, Dugue R, Alonso P, Diombokho A, Joffrois C, Faivre N, Cochet C, and Durand JD. 2014. Analysis of the black-chinned tilapia Sarotherodon melanotheron heudelotii reproducing under a wide range of salinities: from RNA-seq to candidate genes. Molecular Ecology Resources 14:139-149.

403 Bedwal RS, and Bahuguna A. 1994. Zinc, Copper and Selenium in Reproduction. Experientia 404 50:626-640. 
405 Benjamini Y, and Hochberg Y. 1995. Controlling the false discovery rate - a practical and 406 powerful approach to multiple testing. Journal of the Royal Statistical Society Series B$407 \quad$ Methodological 57:289-300.

408 Bobe J, and Labbé C. 2010. Egg and sperm quality in fish. General and Comparative $409 \quad$ Endocrinology 165:535-548.

410 Breckels RD, and Neff BD. 2013. The effects of elevated temperature on the sexual traits, 411 immunology and survivorship of a tropical ectotherm. Journal of Experimental Biology $412 \quad 216: 2658-2664$.

413 Breton TS, Anderson JL, Goetz FW, and Berlinsky DL. 2012. Identification of ovarian gene 414 expression patterns during vitellogenesis in Atlantic cod (Gadus morhua). General and 415 Comparative Endocrinology 179:296-304.

416 Bustin SA, Benes V, Garson JA, Hellemans J, Huggett J, Kubista M, Mueller R, Nolan T, Pfaffl 417 MW, Shipley GL, Vandesompele J, and Wittwer CT. 2009. The MIQE Guidelines: 418 Minimum Information for Publication of Quantitative Real-Time PCR Experiments. $419 \quad$ Clinical Chemistry 55:611-622.

420 Conesa A, Gotz S, Garcia-Gomez JM, Terol J, Talon M, and Robles M. 2005. Blast2GO: a 421 universal tool for annotation, visualization and analysis in functional genomics research. 422 Bioinformatics 21:3674-3676.

423 Cosson J. 2004. The ionic and osmotic factors controlling motility of fish spermatozoa. $424 \quad$ Aquaculture International 12:69-85.

425 Cosson J, Groison AL, Suquet M, Fauvel C, Dreanno C, and Billard R. 2008. Studying sperm 426 motility in marine fish: an overview on the state of the art. Journal of Applied Ichthyology $24: 460-486$.

428 de Lamirande E, Jiang H, Zini A, Kodama H, and Gagnon C. 1997. Reactive oxygen species and 429 sperm physiology. Rev Reprod 2:48-54. 
430 Diouf K, Guilhaumon F, Aliaume C, Ndiaye P, Do Chi T, and Panfili J. 2009. Effects of the 431 environment on fish juvenile growth in West African stressful estuaries. Estuarine $432 \quad$ Coastal and Shelf Science 83:115-125.

433 Dorts J, Grenouillet G, Douxfils J, Mandiki SNM, Milla S, Silvestre F, and Kestemont P. 2012. 434 Evidence that elevated water temperature affects the reproductive physiology of the 435

Evans TG, and Somero GN. 2008. A microarray-based transcriptomic time-course of hyper- and European bullhead Cottus gobio. Fish Physiology and Biochemistry 38:389-399.

442 Fauvel C, Suquet M, and Cosson J. 2010. Evaluation of fish sperm quality. Journal of Applied 443 hypo-osmotic stress signaling events in the euryhaline fish Gillichthys mirabilis: osmosensors to effectors. Journal of Experimental Biology 211:3636-3649.

Fardilha M, Ferreira M, Pelech S, Vieira S, Rebelo S, Korrodi-Gregorio L, Sousa M, Barros A, Silva V, da Cruz e Silva OA, and da Cruz e Silva EF. 2013. "Omics" of human sperm: profiling protein phosphatases. Omics 17:460-472. Ichthyology 26:636-643.

Gauthier SY, Scotter AJ, Lin F-H, Baardsnes J, Fletcher GL, and Davies PL. 2008. A reevaluation of the role of type IV antifreeze protein. Cryobiology 57:292-296.

Gracey AY. 2007. Interpreting physiological responses to environmental change through gene expression profiling. The Journal of Experimental Biology 210:1584-1592.

451 Havird JC, Henry RP, and Wilson AE. 2013. Altered expression of $\mathrm{Na}(+) / \mathrm{K}(+)$-ATPase and other 452 osmoregulatory genes in the gills of euryhaline animals in response to salinity transfer: a meta-analysis of 59 quantitative PCR studies over 10 years. Comp Biochem Physiol Part D Genomics Proteomics 8:131-140. 
455 Hofmann GE, and Todgham AE. 2010. Living in the Now: Physiological Mechanisms to Tolerate 456 a Rapidly Changing Environment. Annual Review of Physiology 72:127-145.

457 Huitorel P, Audebert S, White D, Cosson J, and Gagnon C. 1999. Role of tubulin epitopes in the 458 regulation of flagellar motility. In: Gagnon C, ed. The male gamete: from basic science to 459 clinical applications. Vienna, IL: Cache River Press, 475-491.

460 Lahnsteiner F, Berger B, Weismann T, and Patzner RA. 1998. Determination of semen quality of 461 the rainbow trout, Oncorhynchus mykiss, by sperm motility, seminal plasma parameters, 462 and spermatozoal metabolism. Aquaculture 163:163-181.

463 Larsen PF, Nielsen EE, Williams TD, Hemmer-Hansen J, Chipman JK, Kruhoffer M, Gronkjaer 464 P, George SG, Dyrskjot L, and Loeschcke V. 2007. Adaptive differences in gene 465 expression in European flounder (Platichthys flesus). Molecular Ecology 16:4674-4683.

466 Lazarou M, Thorburn DR, Ryan MT, and McKenzie M. 2009. Assembly of mitochondrial 467 complex I and defects in disease. Biochimica Et Biophysica Acta-Molecular Cell Research 1793:78-88.

469 Lee JK, Kim YJ, Park KS, Shin SC, Kim HJ, Song YH, and Park H. 2011. Molecular and 470 comparative analyses of type IV antifreeze proteins (AFPIVs) from two Antarctic fishes,

473 Legendre M, Cosson J, Hadi Alavi SM, and Linhart O. 2008. Activation of sperm motility in the 474 euryhaline tilapia Sarotherodon melanotheron heudelotii (Dumeril, 1859) acclimatized to Pleuragramma antarcticum and Notothenia coriiceps. Comparative Biochemistry and fresh, sea and hypersaline waters. Cybium:181-182.

Liu JX, Zhai YH, and Gui JF. 2009. Molecular characterization and expression pattern of AFPIV 477 during embryogenesis in gibel carp (Carassius auratus gibelio). Molecular Biology 478 Reports 36:2011-2018. 
479 Loeffen JLCM, Triepels RH, van den Heuvel LP, Schuelke M, Buskens CAF, Smeets RJP, 480 Trijbels JMF, and Smeitink JAM. 1998. cDNA of Eight Nuclear Encoded Subunits of 481 NADH:Ubiquinone Oxidoreductase: Human Complex I cDNA Characterization 482 483 Loftus SJ, and Crawford DL. 2013. Interindividual Variation in Complex I Activity in Fundulus 484 485 486 487 heteroclitus along a Steep Thermocline. Physiological and Biochemical Zoology 86:82Completed. Biochemical and Biophysical Research Communications 253:415-422.

491 91.

Lorin-Nebel C, Avarre JC, Faivre N, Wallon S, Charmantier G, and Durand JD. 2012. Osmoregulatory strategies in natural populations of the black-chinned tilapia Sarotherodon melanotheron exposed to extreme salinities in West African estuaries. Journal of Comparative Physiology B-Biochemical Systemic and Environmental Physiology 182:771-780.

Maranzana E, Barbero G, Falasca AI, Lenaz G, and Genova ML. 2013. Mitochondrial 494 495 Respiratory Supercomplex Association Limits Production of Reactive Oxygen Species from Complex I. Antioxidants \& Redox Signaling 19:1469-1480.

Marchler-Bauer A, and Bryant SH. 2004. CD-Search: protein domain annotations on the fly. Nucleic Acids Res 32:W327-331.

496

Marshall WS, Ossum CG, and Hoffmann EK. 2005. Hypotonic shock mediation by p38 MAPK,

Mochida K, Matsubara T, Andoh T, Ura K, Adachi S, and Yamauchi K. 2002. A novel seminal 500 plasma glycoprotein of a teleost, the Nile tilapia (Oreochromis niloticus), contains a 501 502 partial von Willebrand factor type D domain and a zona pellucida-like domain. Molecular Reproduction and Development 62:57-68. 
503 Morita M, Nakajima A, Takemura A, and Okuno M. 2011. Involvement of redox- and 504 phosphorylation-dependent pathways in osmotic adaptation in sperm cells of euryhaline $505 \quad$ tilapia. Journal of Experimental Biology 214:2096-2104.

506 Morita M, Takemura A, and Okuno M. 2004. Acclimation of sperm motility apparatus in 507 seawater-acclimated euryhaline tilapia Oreochromis mossambicus. Journal of $508 \quad$ Experimental Biology 207:337-345.

509 Oleksiak MF, Churchill GA, and Crawford DL. 2002. Variation in gene expression within and $510 \quad$ among natural populations. Nature Genetics 32:261-266.

511 Pagès J, and Citeau J. 1990. Rainfall and Salinity of a Sahelian Estuary between 1927 and 1987. $512 \quad$ Journal of Hydrology 113:325-341.

513 Panfili J, Mbow A, Durand JD, Diop K, Diouf K, Thior D, Ndiaye P, and Lae R. 2004. Influence 514 of salinity on the life-history traits of the West African black-chinned tilapia 515 (Sarotherodon melanotheron): Comparison between the Gambia and Saloum estuaries. $516 \quad$ Aquatic Living Resources 17:65-74.

517 Panfili J, Thior D, Ecoutin JM, Ndiaye P, and Albaret JJ. 2006. Influence of salinity on the size at 518 maturity for fish species reproducing in contrasting West African estuaries. Journal of $519 \quad$ Fish Biology 69:95-113.

520 Pfaffl MW. 2001. A new mathematical model for relative quantification in real-time RT-PCR. $521 \quad$ Nucleic Acids Research 29:6.

522 Piersma T, and Drent J. 2003. Phenotypic flexibility and the evolution of organismal design. $523 \quad$ Trends in Ecology \& Evolution 18:228-233.

524 Piomboni P, Focarelli R, Stendardi A, Ferramosca A, and Zara V. 2012. The role of mitochondria 525 in energy production for human sperm motility. Int J Androl 35:109-124. 
526 Prathalingam NS, Holt WV, Revell SG, Mirczuk S, Fleck RA, and Watson PF. 2006. Impact of

527 antifreeze proteins and antifreeze glycoproteins on bovine sperm during freeze-thaw.

$528 \quad$ Theriogenology 66:1894-1900.

529 Rathburn CK, Sharp NJ, Ryan JC, Neely MG, Cook M, Chapman RW, Burnett LE, and Burnett

530 KG. 2013. Transcriptomic responses of juvenile Pacific whiteleg shrimp, Litopenaeus

531 vannamei, to hypoxia and hypercapnic hypoxia. Physiological Genomics 45:794-807.

532 Ruiz-Pesini E, Diez C, Lapena AC, Perez-Martos A, Montoya J, Alvarez E, Arenas J, and Lopez-

533 Perez MJ. 1998. Correlation of sperm motility with mitochondrial enzymatic activities.

$534 \quad$ Clinical Chemistry 44:1616-1620.

535 Savenije HHG, and Pages J. 1992. Hypersalinity - a Dramatic Change in the Hydrology of $536 \quad$ Sahelian Estuaries. Journal of Hydrology 135:157-174.

537 Shaliutina A, Gazo I, Cosson J, and Linhart O. 2014. Comparison of oxidant and antioxidant 538 status of seminal plasma and spermatozoa of several fish species. Czech Journal of $539 \quad$ Animal Science In press.

540 Shi YG. 2009. Serine/Threonine Phosphatases: Mechanism through Structure. Cell 139:468-484.

541 Tiedke J, Thiel R, and Burmester T. 2014. Molecular Response of Estuarine Fish to Hypoxia: A 542 Comparative Study with Ruffe and Flounder from Field and Laboratory. Plos One $5439: 990778$.

544 Tiersch TR, and Yang HP. 2012. Environmental salinity-induced shifts in sperm motility 545 activation in Fundulus grandis. Aquaculture 324:145-150.

546 Tine M, Bonhomme F, McKenzie DJ, and Durand J-D. 2010. Differential expression of the heat 547 shock protein Hsp70 in natural populations of the tilapia, Sarotherodon melanotheron, 548 acclimatised to a range of environmental salinities. BMC ecology 10:11-11. 
549 Tine M, de Lorgeril J, D'Cotta H, Pepey E, Bonhomme F, Baroiller JF, and Durand JD. 2008. 550 Transcriptional responses of the black-chinned tilapia Sarotherodon melanotheron to $551 \quad$ salinity extremes. Marine Genomics 1:37-46.

552 Tine M, Guinand B, and Durand JD. 2012. Variation in gene expression along a salinity gradient 553 in wild populations of the euryhaline black-chinned tilapia Sarotherodon melanotheron. $554 \quad$ Journal of Fish Biology 80:785-801.

555 Tine M, McKenzie DJ, Bonhomme F, and Durand J-D. 2011. Salinity-related variation in gene 556 expression in wild populations of the black-chinned tilapia from various West African coastal marine, estuarine and freshwater habitats. Estuarine Coastal and Shelf Science 91:102-109.

Tingaud-Sequeira A, Chauvigne F, Lozano J, Agulleiro M, Asensio E, and Cerda J. 2009. New

Vandesompele J, De Preter K, Pattyn F, Poppe B, Van Roy N, De Paepe A, and Speleman F. 563 2002. Accurate normalization of real-time quantitative RT-PCR data by geometric averaging of multiple internal control genes. Genome Biology 3:research0034.0031 research0034.0011.

Watson ML, Zinn AR, Inoue N, Hess KD, Cobb J, Handel MA, Halaban R, Duchene CC, insights into molecular pathways associated with flatfish ovarian development and atresia revealed by transcriptional analysis. BMC Genomics 10:434. Albright GM, and Moreadith RW. 1998. Identification of morc (microrchidia), a mutation that results in arrest of spermatogenesis at an early meiotic stage in the mouse. Proceedings of the National Academy of Sciences 95:14361-14366.

West-Eberhard MJ. 2003. Developmental Plasticity and Evolution. Oxford, UK: Oxford University Press. populations. Genome Biology 6:14. 
574 Whitehead A, and Crawford DL. 2006. Neutral and adaptive variation in gene expression. 575 Proceedings of the National Academy of Sciences of the United States of America $576 \quad 103: 5425-5430$.

577 Whitehead A, Roach JL, Zhang S, and Galvez F. 2011. Genomic mechanisms of evolved 578 physiological plasticity in killifish distributed along an environmental salinity gradient. 579 Proceedings of the National Academy of Sciences of the United States of America $580 \quad 108: 6193-6198$.

581 Whiterod NR, and Walker KF. 2006. Will rising salinity in the Murray-Darling Basin affect 582 common carp (Cyprinus carpio L.)? Marine and Freshwater Research 57:817-823.

583 Yamaguchi S, Miura C, Kikuchi K, Celino FT, Agusa T, Tanabe S, and Miura T. 2009. Zinc is an 584 essential trace element for spermatogenesis. Proceedings of the National Academy of 585 Sciences of the United States of America 106:10859-10864.

586 


\section{1}

Figure 1

Origin of the 2 series of experimental animals considered in this study, which both originated from a single stock maintained in captivity in freshwater since $\sim 15$ years (see text for details). T animals result from a transfer from fish of this stock to the same (0) or to different salinity conditions ( 35 and 70). B animals represent first-generation male offspring from the reproduction of each category of $\mathrm{T}$ fish under their respective salinity conditions $(0,35$ or 70$)$. Number of $\mathrm{T}$ and $\mathrm{B}$ males collected from each salinity condition is reported in brackets.

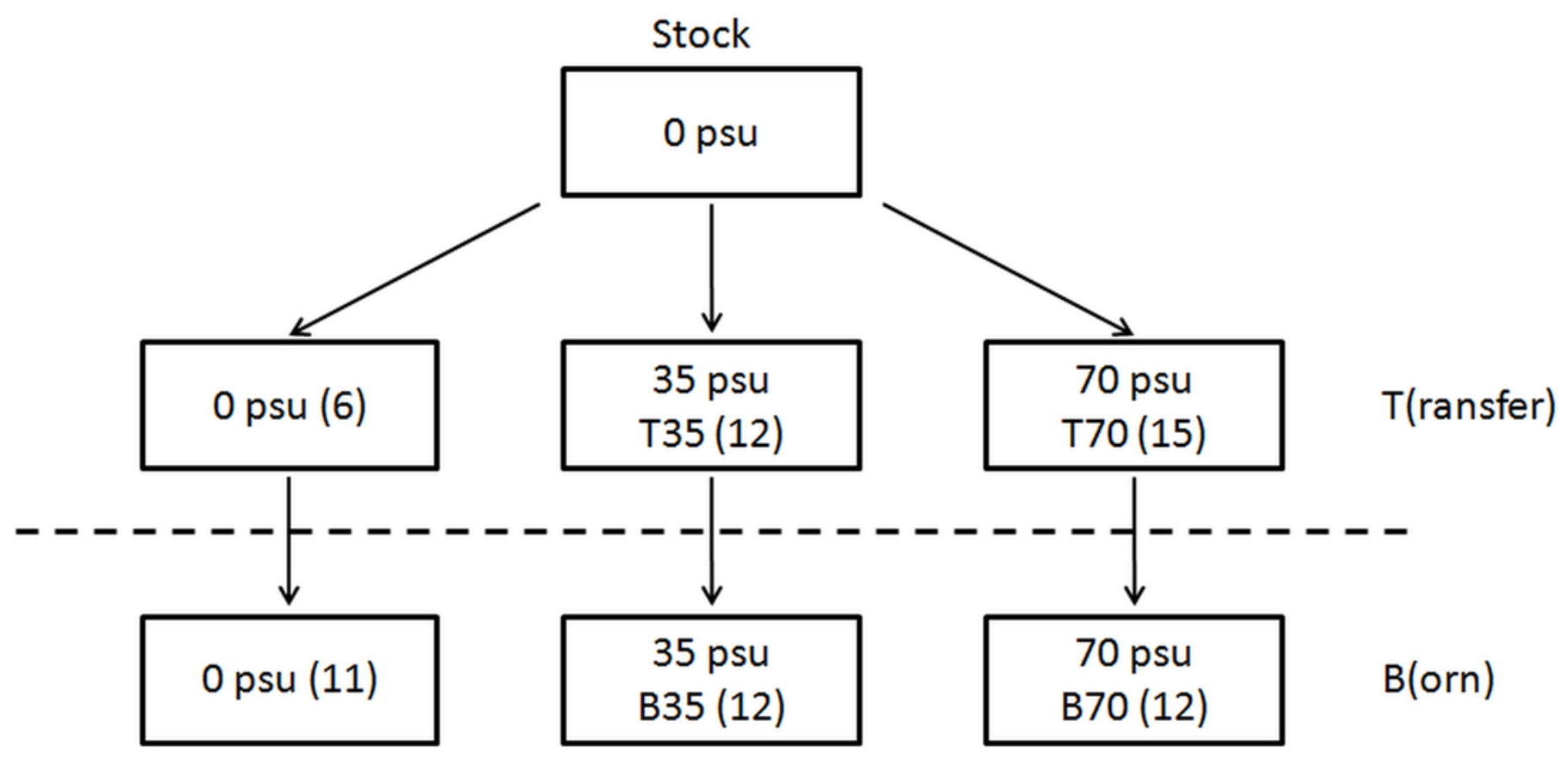




\section{2}

Figure 2

Expression variations according to salinity of the 20 significant genes for $T$ animals. Values are expressed as relative expression \pm SD. Original sequence names may be found in table 1. Bars are colored according to the salinity condition (red: freshwater; green: seawater; blue: hypersaline water). Identical letters indicate no significant differences (according to a Tukey-Kramer's post-ANOVA test) between salinities.

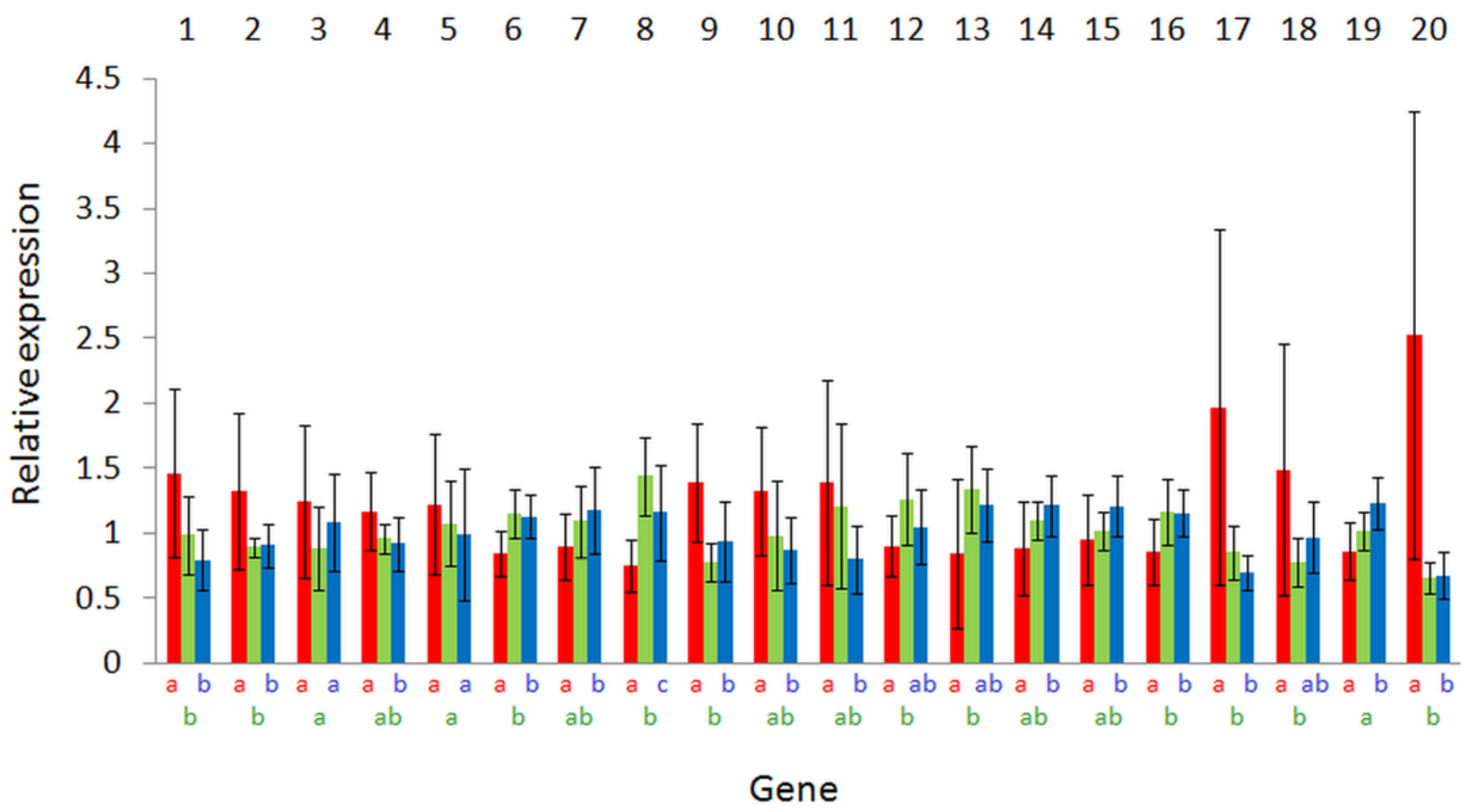




\section{3}

Figure 3

Expression variations according to salinity of the 20 significant genes for $B$ animals. Values are expressed as relative expression $\pm \mathrm{SD}$. Original sequence names may be found in table 1. Bars are colored according to the salinity condition (red: freshwater; green: seawater; blue: hypersaline water). Identical letters indicate no significant differences (according to a Tukey-Kramer's post-ANOVA test) between salinities.

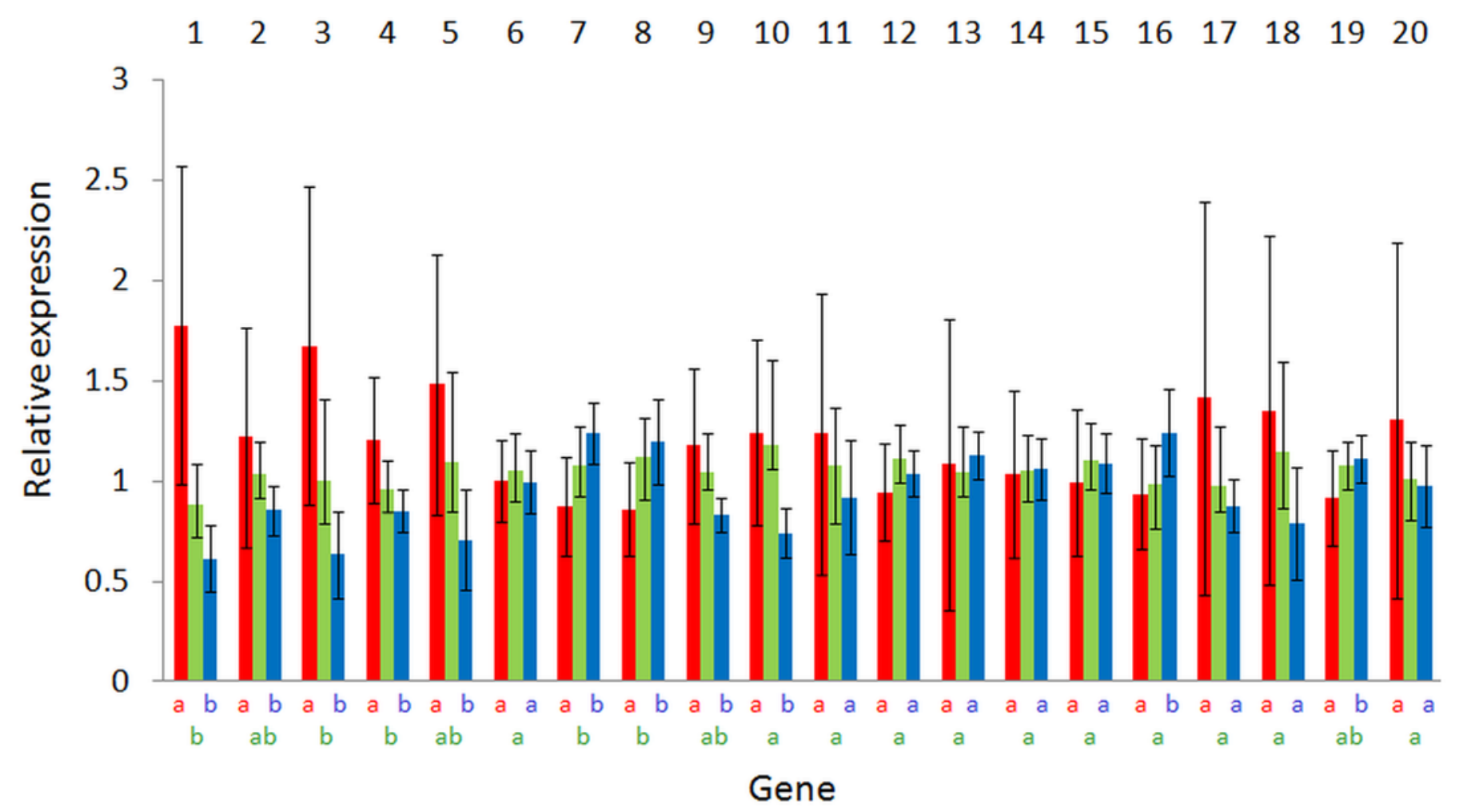




\section{4}

Figure 4

Principal component analysis of the 6 fish groups according to their gene expression pattern. The first axis accounted for $87.20 \%$ of the total variance and the second axis for $5.40 \%$. The ellipses include $95 \%$ of the variance within each group, and the stars represent the gravity center of each ellipse. According to a Tukey-Kramer's pairwise comparison test performed on the principal component scores of the first axis, freshwater animals (group 0 ) are significantly differentiated from those of groups T35 $(P=0.024), T 70(P=0.0015)$ and $B 70(P=0.0004)$.

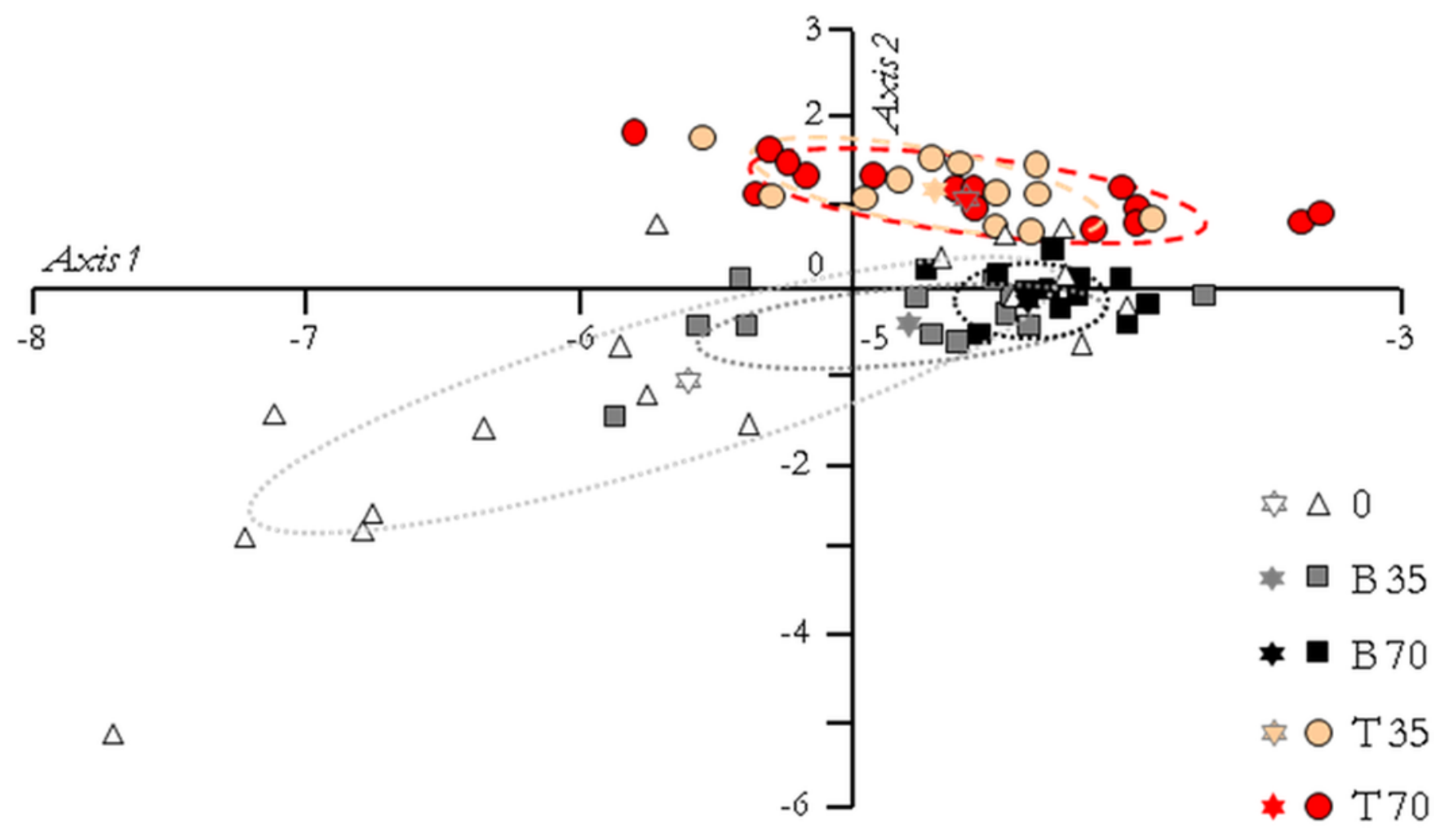




\section{Table $\mathbf{1}$ (on next page)}

Table 1

List of genes showing significant differential expression between salinities in the two fish generations ( $\mathrm{T}$ and $\mathrm{B}$ ) and corresponding statistical values 


\section{PeerJ Reviewing Manuscript}

Table 1. List of genes showing significant differential expression between salinities in the two fish generations (T and B) and corresponding statistical values

\begin{tabular}{|c|c|c|c|}
\hline \multirow[t]{2}{*}{ Original sequence name $^{\mathrm{a}}$} & \multirow[t]{2}{*}{ Gene $\#^{b}$} & \multicolumn{2}{|c|}{ Corrected ANOVA $p$-values } \\
\hline & & T animals & $\mathrm{B}$ animals \\
\hline Contig_Tilapia_90_6346 & 1 & $1.34 \mathrm{E}-03$ & $3.12 \mathrm{E}-05$ \\
\hline Contig_Tilapia_90_8891 & 2 & $8.76 \mathrm{E}-03$ & $7.60 \mathrm{E}-02$ \\
\hline Contig_Tilapia_90_947 & 3 & $1.46 \mathrm{E}-01$ & $6.70 \mathrm{E}-04$ \\
\hline Contig_Tilapia_90_6938 & 4 & $1.29 \mathrm{E}-02$ & $1.97 \mathrm{E}-03$ \\
\hline Contig_Tilapia_90_21432 & 5 & $3.84 \mathrm{E}-01$ & $3.17 \mathrm{E}-03$ \\
\hline Contig_Tilapia_90_1393 & 6 & $7.53 \mathrm{E}-05$ & 7.67E-01 \\
\hline Contig_Tilapia_90_10643 & 7 & $3.13 \mathrm{E}-02$ & $1.06 \mathrm{E}-03$ \\
\hline Transcript_AVA3_33497 & 8 & $1.28 \mathrm{E}-05$ & $1.60 \mathrm{E}-03$ \\
\hline Transcript_AVA1_24409 & 9 & $2.02 \mathrm{E}-04$ & $1.75 \mathrm{E}-02$ \\
\hline Contig_Tilapia_90_26617 & 10 & $1.29 \mathrm{E}-02$ & $1.03 \mathrm{E}-02$ \\
\hline Contig_Tilapia_90_2414 & 11 & $3.38 \mathrm{E}-02$ & $3.35 \mathrm{E}-01$ \\
\hline Contig_Tilapia_90_2253 & 12 & $1.29 \mathrm{E}-02$ & $1.08 \mathrm{E}-01$ \\
\hline Contig_Tilapia_90_2777 & 13 & $1.29 \mathrm{E}-02$ & $9.62 \mathrm{E}-01$ \\
\hline Contig_Tilapia_90_8343 & 14 & $1.05 \mathrm{E}-02$ & $9.73 \mathrm{E}-01$ \\
\hline Transcript_AVA1_58357 & 15 & $3.38 \mathrm{E}-02$ & $5.67 \mathrm{E}-01$ \\
\hline Contig_Tilapia_90_26561 & 16 & $1.34 \mathrm{E}-03$ & $1.07 \mathrm{E}-02$ \\
\hline Contig_Tilapia_90_27008 & 17 & $7.76 \mathrm{E}-04$ & $1.08 \mathrm{E}-01$ \\
\hline Contig_Tilapia_90_1736 & 18 & $1.32 \mathrm{E}-02$ & $1.08 \mathrm{E}-01$ \\
\hline Contig_Tilapia_90_7359 & 19 & $1.54 \mathrm{E}-04$ & $2.65 \mathrm{E}-02$ \\
\hline Contig_Tilapia_90_2321 & 20 & $7.53 \mathrm{E}-05$ & $3.35 \mathrm{E}-01$ \\
\hline
\end{tabular}

${ }^{a}$ Names of the sequences as they appear at http://asahttp.drim.com/tilapia/tilapia_menu.php.

${ }^{\mathrm{b}}$ This gene numbering is used in Table 2, figures 2 and 3 and all along the manuscript in order to facilitate reading. 
PeerJ Reviewing Manuscript 


\section{Table 2 (on next page)}

Table 2

Annotation features of the 20 responsive and 4 reference genes 
Table 2. Annotation features of the 20 responsive and 4 reference genes

\begin{tabular}{|c|c|c|c|c|c|c|}
\hline & Sequence & \#Blast & & Best hit & & \#GO \\
\hline Gene \# & length (nt) & X hits ${ }^{\mathrm{a}}$ & Protein description ${ }^{\mathrm{b}}$ & accession & E-Value & terms \\
\hline \multicolumn{7}{|c|}{ Differentially expressed genes } \\
\hline 1 & 353 & 16 & PREDICTED: type-4 ice-structuring protein-like & XP_004549213 & $1.06533 \mathrm{E}-61$ & 2 \\
\hline 2 & 584 & 20 & PREDICTED: tubulin-specific chaperone A-like & XP_003455155 & 4.68328E-50 & 5 \\
\hline 3 & 524 & 20 & sodium/potassium-transporting ATPase alpha-1 subunit & AGO02179 & $4.12826 \mathrm{E}-87$ & 20 \\
\hline 4 & 289 & 20 & Serine/threonine-protein phosphatase 6 catalytic subunit & ELW48549 & $1.44788 \mathrm{E}-46$ & 6 \\
\hline 5 & 164 & 20 & PREDICTED: sperm plasma glycoprotein 120 & XP_004574936 & $4.12231 \mathrm{E}-23$ & 0 \\
\hline 6 & 849 & 20 & PREDICTED: proteasome subunit alpha type-5-like & XP_003441568 & $8.42686 \mathrm{E}-175$ & 19 \\
\hline 7 & 459 & 20 & PREDICTED: neuroserpin-like & XP_004561427 & $1.13288 \mathrm{E}-76$ & 4 \\
\hline 8 & 177 & 1 & Hypothetical protein & XP_004563130 & $5.19086 \mathrm{E}-18$ & 0 \\
\hline 9 & 260 & 20 & PREDICTED: NADH dehydrogenase [ubiquinone] 1 beta subcomplex subunit 3-like & XP_003457472 & $8.68852 \mathrm{E}-26$ & 2 \\
\hline 10 & 179 & 20 & NADH dehydrogenase subunit 1 & ADR10264 & 3.32857E-21 & 4 \\
\hline 11 & 604 & 20 & PREDICTED: hypoxia-induced gene domain family member 1A-like & XP_003438136 & 4.44514E-47 & 1 \\
\hline 12 & 545 & 20 & heat-shock protein 90 & CAX33858 & $8.51839 \mathrm{E}-92$ & 34 \\
\hline 13 & 1010 & 20 & heat shock protein 70 & ACI42865 & 0.0 & 3 \\
\hline 14 & 506 & 20 & PREDICTED: glutathione S-transferase theta-1-like & XP_004572434 & $1.57519 \mathrm{E}-28$ & 1 \\
\hline 15 & 321 & 20 & PREDICTED: calcium-binding protein 39-like isoform X1 & XP_004573664 & $6.54477 \mathrm{E}-61$ & 8 \\
\hline 16 & 230 & 20 & beta tubulin & BAD11697 & 7.71535E-48 & 7 \\
\hline 17 & 313 & 20 & PREDICTED: MORC family $\mathrm{CW}$-type zinc finger protein 2A-like & XP_004544577 & $5.08988 \mathrm{E}-31$ & 2 \\
\hline 18 & 1105 & 20 & PREDICTED: nucleolar protein 56-like & XP_004545283 & $3.59979 \mathrm{E}-151$ & 8 \\
\hline 19 & 465 & 20 & PREDICTED: 28 kDa heat- and acid-stable phosphoprotein-like & XP_003443172 & 4.92124E-54 & 4 \\
\hline 20 & 512 & 0 & - & - & - & 0 \\
\hline \multicolumn{7}{|c|}{ Reference genes } \\
\hline $\mathrm{R} 1$ & 291 & 20 & PREDICTED: NADH dehydrogenase [ubiquinone] flavoprotein 1, mitochondrial-like & XP_003452502 & $5.14723 \mathrm{E}-58$ & 8 \\
\hline $\mathrm{R} 2$ & 299 & 20 & $\begin{array}{l}\text { PREDICTED: NADH dehydrogenase [ubiquinone] } 1 \text { alpha subcomplex subunit } 10 \text {, } \\
\text { mitochondrial-like }\end{array}$ & XP_004571622 & $7.27748 \mathrm{E}-52$ & 6 \\
\hline R3 & 265 & 20 & PREDICTED: tubulin beta-4B chain & XP_004005609 & $1.57111 \mathrm{E}-59$ & 21 \\
\hline R4 & 323 & 20 & PREDICTED: cytochrome $\mathrm{c}$ oxidase subunit $6 \mathrm{C}-1$-like & XP 003451899 & $3.40807 \mathrm{E}-36$ & 6 \\
\hline
\end{tabular}

${ }^{a}$ The number of BlastX hits was limited to 20 . 
${ }^{\mathrm{b}}$ According to the best blast hit.

Peer) reviewing PDF | (v2014:10:2896:1:1:NEW 26 Nov 2014) 